\title{
A test of Allen's rule in subterranean mammals: The genus Ctenomys (Caviomorpha, Ctenomyidae)
}

Article in Mammalia · November 2011

DOI: 10.1515/MAMM.2011.044

CITATIONS

2

3 authors:

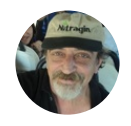

Claudio Bidau

Fundação Oswaldo Cruz

117 PUBLICATIONS 1,007 CITATIONS

SEE PROFILE

Alonso Ismael Medina

National University of Comahue - CONICET

10 PUBLICATIONS 60 CITATIONS

SEE PROFILE
READS

\section{Dardo A. Martí}

National Scientific and Technical Research ...

79 PUBLICATIONS 523 CITATIONS

SEE PROFILE 


\section{A test of Allen's rule in subterranean mammals: the genus Ctenomys (Caviomorpha, Ctenomyidae)}

\author{
Claudio J. Bidau ${ }^{1, a, *}$, Dardo A. Martí ${ }^{2,4}$ and \\ Alonso I. Medina ${ }^{3,4}$ \\ ${ }^{1}$ Instituto Oswaldo Cruz, FIOCRUZ, Rio de Janeiro, \\ Laboratório de Biologia e Parasitologia de Mamíferos \\ Silvestres Reservatórios, Av. Brasil 4365, Pav. Arthur \\ Neiva, sala 14, Manguinhos, Rio de Janeiro, RJ-21045- \\ 900, Brazil, e-mail: bidau47@yahoo.com \\ ${ }^{2}$ Laboratorio de Genética Evolutiva, Facultad de Ciencias \\ Exactas, Químicas y Naturales, Universidad Nacional de \\ Misiones, 3300 Posadas, Argentina \\ ${ }^{3}$ Instituto de Biología Marina y Pesquera "Almirante \\ Storni”, 8520 San Antonio Oeste, Rio Negro, Argentina \\ ${ }^{4}$ Consejo Nacional de Investigaciones Científicas y \\ Técnicas, Buenos Aires, Argentina \\ *Corresponding author
}

\begin{abstract}
We tested the applicability of Allen's rule in 47 species and 32 unnamed forms (populations that are probably good species or undefined taxa within a superspecies or species group) of the South American subterranean Hystricomorph rodents of the genus Ctenomys (tuco-tucos) (Rodentia: Ctenomyidae) by analyzing tail length in relation with head and body length, and body mass. Tail length allometry was analyzed by Reduced Major Axis regression while the possible correlation of relative tail length with temperature, precipitation and evapotranspiration variables was explored through Simultaneous Autoregression to account for spatial autocorrelations. Our results indicate that tuco-tucos do not follow Allen's rule but its converse, tail proportion relative to body mass increasing with latitude while body size decreases in the same direction (the trend is similar for tail length relative to head and body length but not statistically significant). Regarding climatic variables, the main predictors of relative tail length were temperature and evapotranspiration variables with trends confirming the positive (non-Allenian) correlation of relative tail length with latitude. We conclude that tuco-tucos, being almost fully subterranean, thermoregulate behaviorally by maintaining constant temperatures within their burrows independent of geographic location. The former confirms previous results that indicated that Ctenomys follows the converse to Bergmann's rule. Relative tail length variation would be a result of simple allometric growth.
\end{abstract}

${ }^{a}$ Present address: Universidad Nacional de Río Negro, Sede Alto Valle, Subsede Villa Regina, Tacuarí 669, 8336 Villa Regina, Río Negro, Argentina.
Keywords: allometry; body proportions; climate; geographic cline; subterranean rodent.

\section{Introduction}

Allen's rule (Allen 1877, 1905, Mayr 1999) is an empirical geographical pattern according to which, protruding body parts of endothermic animals, such as tails, limbs, ears, bills, etc. tend to be relatively shorter in the cooler parts of the range of a taxon than in its warmer parts. This ecogeographical rule has been considered traditionally as a complement to Bergmann's rule (Bergmann 1847), but has received less attention than the former. Nevertheless, a small number of studies have demonstrated the existence of Allenian clines in endotherms (birds: Snow 1954, Merilä 1977, Raveling and Warner 1978, McGillivray 1989, Bried and Jouventin 1997, Laiolo and Rolando 2001, Cartar and Morrison 2005, YomTov et al. 2006; mammals: Mitchell 1971, Griffing 1974, Ramey and Nash 1976, Stevenson 1986, Lindsay 1987, Ellison et al. 1993, Vrba 1996, Wiggington and Dobson 1999) and also ectotherms (Ray 1960, Salthe and Crump 1977). Both rules as originally interpreted, considered that the increase in body size (Bergmann's rule) and the decrease in the proportions of protruding body parts towards higher latitudes and altitudes conformed to thermoregulation (i.e., heat conservation or the avoiding of heat loss). For Bergmann's rule, a number of alternative explanations other than thermoregulation have been proposed (Ashton et al. 2000, Meiri and Dayan 2003, Medina et al. 2007) many of which could be readily related also to Allen's rule. Both rules, which have been alternatively considered in inter- or intraspecific applications (Blackburn et al. 1999), with exceptions in different animal groups reported.

Classically, natural selection for thermoregulatory adaptation has been invoked as the essential cause of Allen geographical patterns. Experimental evidence of the former hypothesis has recently been obtained for humans (Tilkens et al. 2007). The authors demonstrated that shorter limbs help reduce the metabolic cost of maintaining body temperature, while longer limbs cause greater heat dissipation independent of the effect of mass. Nevertheless, other factors could be involved. Recently, Serrat et al. (2008) demonstrated that in laboratory mice, appendage outgrowth is also markedly influenced by environmental temperature. Vasomotor changes would control limb length indirectly through their effects on appendage temperature. Thus, clinal distributions of limb length following the Allen's rule trend, may represent a complex amalgam of genetic assimilation after generations of selection combined with direct temperature responses in growing cartilage. 
Tuco-tucos (genus Ctenomys de Blainville, 1826) constitute a useful model to test predictions about relationships between body size and environmental variables. The genus includes at least 62 species, showing a wide variation in body size and an enormous geographic distribution spanning across $45^{\circ}$ of southern latitude from ca. $-10^{\circ}$ in the Peruvian highlands to almost $-55^{\circ}$ in Tierra del Fuego). Populations are found between $0 \mathrm{~m}$ and $5000 \mathrm{~m}$ above sea level from the Pacific to the Atlantic coasts (Contreras and Bidau 1999, Bidau 2006, 2011). These rodents are fully subterranean spending more than $95 \%$ of their lives underground (Nevo 1999) and are morphologically homogeneous, all species showing the same adaptations for living underground although varying greatly in size (Medina et al. 2007). Furthermore, tuco-tucos inhabit an enormous variety of habitats and climates and although localized populations may be subjected to intense environmental selection resulting from differences in soil texture and depth, available food plants, intensity of predation, etc. their burrows maintain fairly constant temperature and humidity independently of geographic location (Reig et al. 1990, Nevo 1999, Busch et al. 2000, Bidau 2006, Medina et al. 2007). This characteristic probably isolates them quite effectively from the external environment much more than other subterranean rodents (Medina et al. 2007). Finally, it has recently been demonstrated that tuco-tucos follow the converse to Bergmann's rule (Medina et al. 2007).

Similar to other subterranean mammalian taxa, the Ctenomyidae exhibit a complex set of adaptations to the underground milieu that include not only specialized morphological, physiological and biochemical characteristics (Reig et al. 1990, Nevo 1999, Sedlácek 2007a,b) but also specialized behaviors regarding burrow construction and maintenance of its internal microclimate (Burda 2007). The aim of this study was to test for Allen's rule across these rodents' wide geographical distribution considering that Ctenomys species thermoregulate essentially controlling temperature within their burrows and not by changes in body size.

\section{Materials and methods}

\section{Study species and morphometric traits}

We based this study on 719 specimens of Ctenomys belonging to 133 natural populations including 47 named species and 32 unnamed or undescribed forms (the term "form" is used here to denote populations that are probably good species or undefined taxa within a superspecies or species group; see Mirol et al. 2010) from Argentina, Bolivia, Chile, Paraguay and Uruguay sampled by the authors and collaborators (Medina et al. 2007) or obtained from the literature (see Figure 1 and Appendix 1 in Medina et al. 2007). External measurements of all specimens included Total Body (TL) and Head plus Body (HB), and Tail (T) lengths. In most individuals, body mass (BM) was also measured or obtained from the literature. The proportions of TL relative to $\mathrm{HB}$ and $\mathrm{BM}$ were calculated for all individuals and arcsin transformed. Males and females were analyzed separately since all tuco-tuco species exhibit male-biased sexual size dimorphism (SSD) which decreases significantly towards South following the converse Bergmannian pattern of the genus but conforming Rensch's rule (Bidau and Medina, submitted).

\section{Independent variables}

For each studied locality, latitude (LAT) and longitude (LON) were recorded and transformed to decimal units. Altitude was recorded as metres above sea level. However, onedimensional analyses have no explanatory power (Hawkins and Diniz-Filho 2004), because size clines may obey to multiple selection pressures that are not only dependent on temperature constraints but also on other climatic and biotic factors that could influence body size as explained above (Jones et al. 2005). Therefore we considered other independent variables as follows. Environmental variables for each locality included: mean annual temperature (TMEA), mean minimal and maximal temperatures (TMIN, TMAX), mean temperature of the dry season (Tdry), total annual precipitation (PANN), minimal and maximal precipitation (PMIN, PMAX) and mean rainfall of the dry season (Pdry) (Cramer and Leemans 2001). To estimate seasonality, we calculated the annual variability of the climatic factors. Annual variability of temperature was estimated through the coefficient of variation $(\mathrm{CV}=\mathrm{SD} * 100 / \mathrm{x})(\mathrm{CVT}$; where $\mathrm{x}$ in this case, is the mean annual temperature of each sampled locality, and SD its standard deviation), and the difference between average maximum and minimum annual temperatures (TM-m). We assessed variability of precipitation by the $\mathrm{CV}$ of mean annual precipitation (CVP, calculated from mean monthly precipitation and its SD), and the difference between maximum and minimum average monthly precipitation (PM-m).

Because body size clines may be correlated with primary productivity and ambient energy, two correlates of actual (AET) and potential (PET) evapotranspiration were considered (Rosenzweig 1968, Olalla-Tárraga et al. 2006, Rodríguez et al. 2006). Therefore, we obtained for each geographic point, AET, an estimator of primary productivity (calculated by the Thornthwaite formula), PET, a measure of ambient energy (calculated by the Priestley-Taylor equation), and Water Balance (WB). We used vectors, databases and maps for AET, PET and WB from Ahn and Tateishi (1994a,b). Data analysis was performed with the Geomatica FreeView V. 10.0 software by PCI Geomatics, Ontario, Canada (www. pcigeomatics.com). All data are in $\mathrm{mm} /$ year. Mean annual AET, PET and WB values were calculated for each sampled locality. To analyze tail length allometry we used Reduced Major Axis regression (RMA) to estimate slopes for the relationship between $\log _{10}$ (TL) and $\log _{10}$ (HB or BM) employing the software of Bohonak and van der Linde (2004). Clarke's t statistic with adjusted degrees of freedom was used for testing the null hypothesis that $b_{\mathrm{RMA}}=1.0$ for the linear relationship $\mathrm{TL} / \mathrm{HB}$, and $\mathrm{b}_{\mathrm{RMA}}=0.33$ for TL/BM (Clarke 1980).

Because most environmental variables show a high degree of colinearity, dimensionality of the predictors was reduced by means of Principal Component Analyses (PCA). We established the number of principal components retained and later used as predictors in correlation/regression analyses, by the 


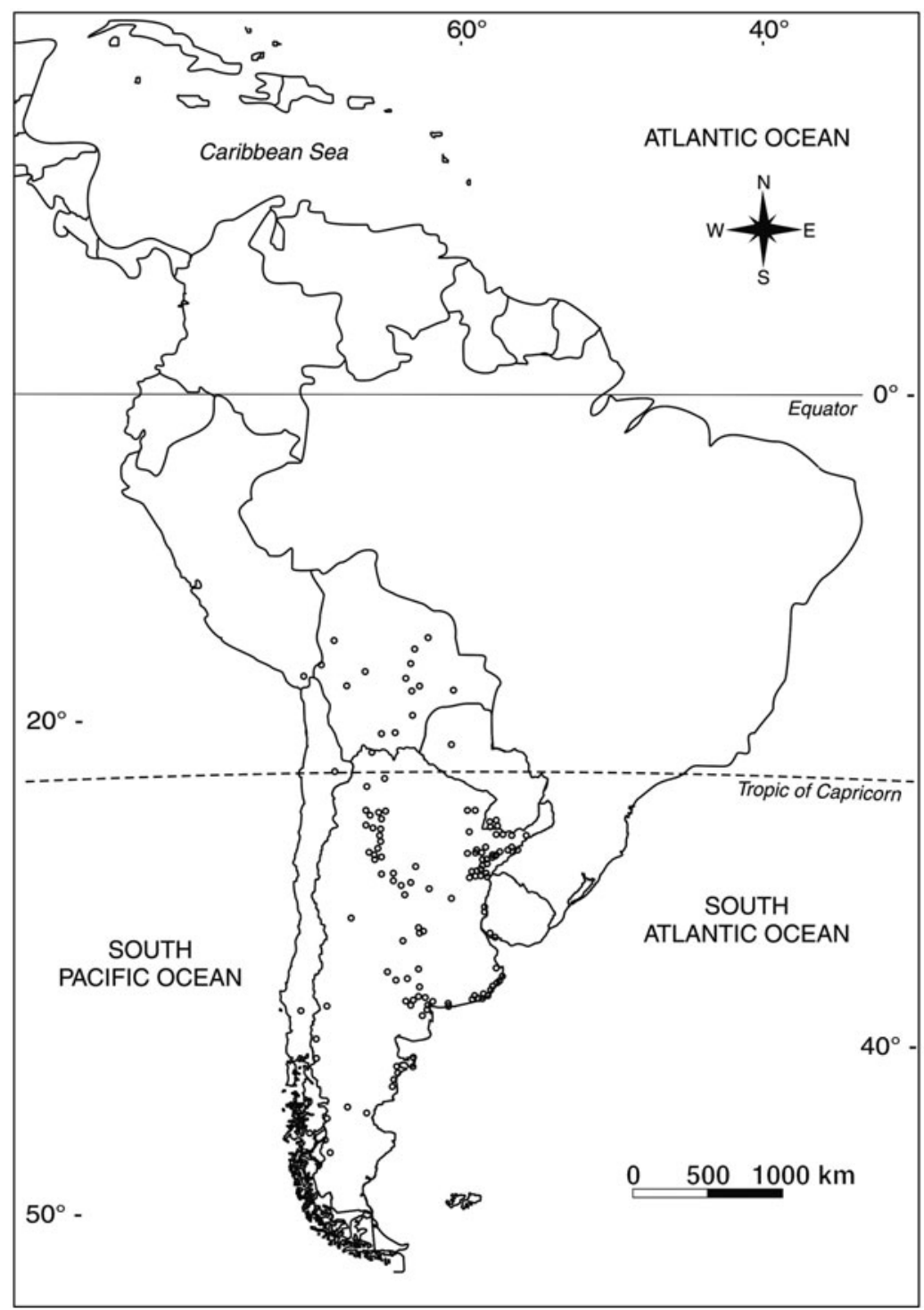

Figure 1 Geographic distribution of Ctenomys populations studied in this paper. See Medina et al. (2007) for references to all localities.

Table 1 RMA regressions of tail length on head and body length, and body mass for population means of males and females of 112 and 114 Ctenomys populations.

\begin{tabular}{|c|c|c|c|c|c|c|c|c|c|c|c|c|}
\hline \multirow[t]{2}{*}{ Trait 1} & \multirow[t]{2}{*}{ Trait 2} & \multicolumn{4}{|c|}{ Correlation coefficient } & \multicolumn{5}{|c|}{ RMA slope } & \multicolumn{2}{|c|}{ RMA intercept } \\
\hline & & $\mathrm{r}$ & $\mathrm{t}$ & df & p-Value & $\beta(\mathrm{SE})$ & $\mathrm{T}$ & $\mathrm{df}^{1}$ & $\mathrm{p}$-Value & $95 \% \mathrm{CI}$ & $\mathrm{a}(\mathrm{SE})$ & $95 \% \mathrm{CI}$ \\
\hline \multirow[t]{2}{*}{ Male TL } & HBL & 0.610 & 8.07 & 110 & $<0.001$ & $\begin{array}{l}0.996 \\
(0.075)\end{array}$ & 0.09 & 95.99 & $\mathrm{~ns}$ & $0.847,1.145$ & $\begin{array}{l}-0.374 \\
(0.169)\end{array}$ & $\begin{array}{l}-0.710 \\
-0.038\end{array}$ \\
\hline & $\mathrm{BM}$ & 0.948 & 25.67 & 74 & $<0.001$ & $\begin{array}{l}0.325 \\
(0.012)\end{array}$ & 0.30 & 53.74 & ns & $0.301,0.349$ & $\begin{array}{c}1.668 \\
(0.028)\end{array}$ & $\begin{array}{l}1.613 \\
1.723\end{array}$ \\
\hline \multirow[t]{2}{*}{ Female TL } & HBL & 0.634 & 8.50 & 112 & $<0.001$ & $\begin{array}{l}1.220 \\
(0.089)\end{array}$ & 3.02 & 96.09 & 0.0032 & $1.043,1.397$ & $\begin{array}{l}-0.865 \\
(0.199)\end{array}$ & $\begin{array}{r}-0.846 \\
0.245\end{array}$ \\
\hline & $\mathrm{BM}$ & 0.686 & 8.28 & 77 & $<0.001$ & $\begin{array}{l}0.303 \\
(0.025)\end{array}$ & 0.42 & 65.13 & ns & $0.253,0.353$ & $\begin{array}{c}1.202 \\
(0.056)\end{array}$ & $\begin{array}{l}1.091 \\
1.313\end{array}$ \\
\hline
\end{tabular}

a, RMA intercept; $\beta$, RMA slope; BM, body mass (all variables were log-transformed); CI, confidence interval; df, degrees of freedom; $\mathrm{df}^{1}$, adjusted degrees of freedom; HB, head and body length; ns, non-significant; p, probability; r, Pearson's correlation coefficient; SE, Standard error; t, Student's t-statistic; T, Clarke's T-statistic; TL, tail length. 

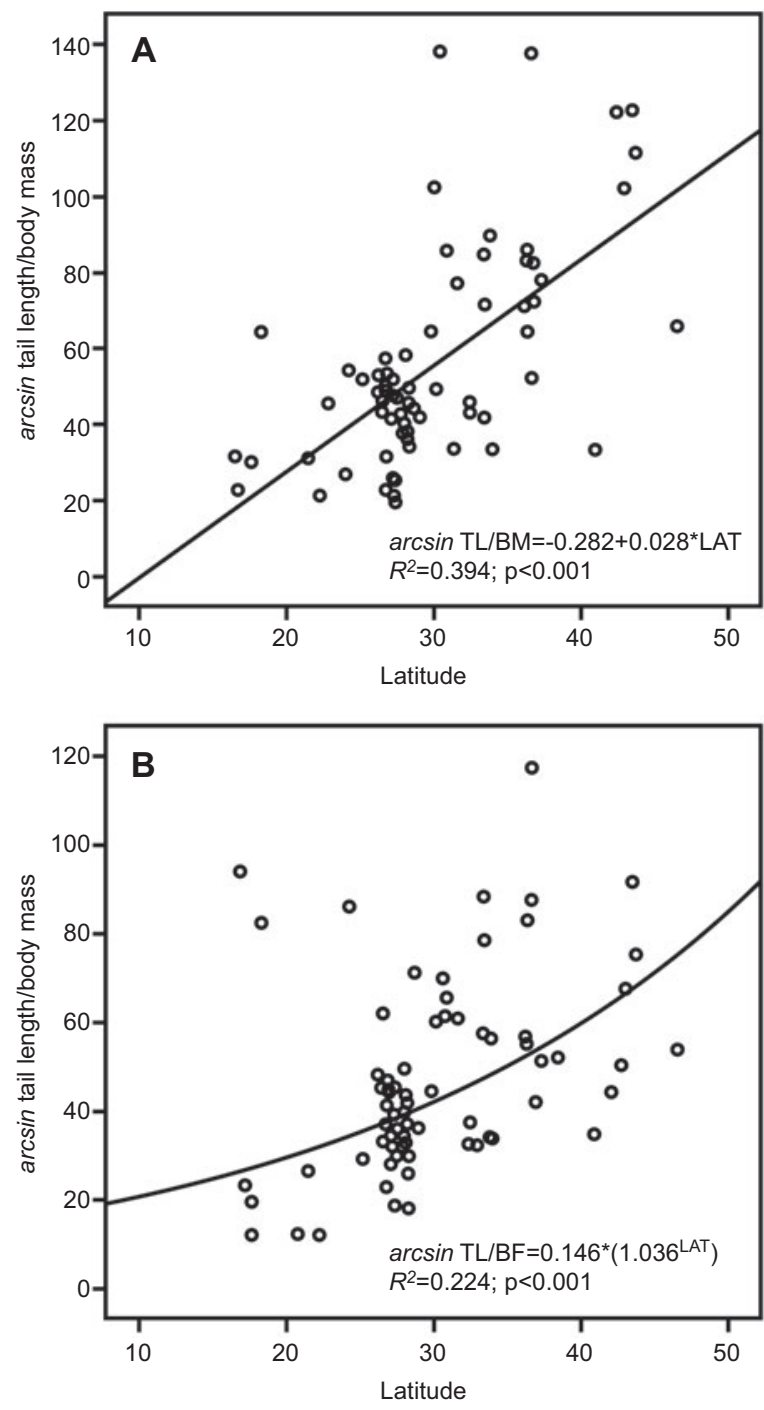

Figure 2 Regressions between the proportion of tail length to body mass (expressed as $\arcsin ^{*} 100$ ) and latitude in males (A) and females (B) of Ctenomys. For males, the best regression model was linear while for females, exponential.

broken-stick criterion (Legendre and Legendre 1998). To improve interpretation of the principal components, they were rotated to simple structure using VARIMAX criterion (Kline 1994). After identification of the best PCA predictors, the best model (combination of variables with high loadings in that PCA) was identified using Akaike's Information Criterion (Burnham and Anderson 2002).

Most biogeographic and macroecological data are spatially autocorrelated (Legendre 1993, Diniz-Filho et al. 2003, Rangel et al. 2006) thus, special statistical procedures are required for hypothesis testing, such as Simultaneous Autoregression (SAR) with preset coordinate variables (LON, LAT). In this paper, we performed all spatial analyses in SAM v.3 (Spatial Analysis in Macroecology) (Rangel et al. 2006). Finally, independent contrasts (although desirable) were not used because until now, there is not a published comprehensive phylogeny
Table 2 Principal components analyses of climatic data for species and populations of Ctenomys.

\begin{tabular}{llllll}
\hline Climatic variables & \multicolumn{3}{l}{ Principal components (broken stick) } \\
\cline { 2 - 3 } & \multicolumn{2}{l}{ Male data } & & \multicolumn{2}{l}{ Female data } \\
\cline { 2 - 3 } \cline { 5 - 6 } & PC1 & PC2 & & PC1 & PC2 \\
\hline AET & $0.907^{*}$ & -0.018 & & $0.918^{*}$ & -0.003 \\
PET & $0.696^{*}$ & -0.318 & & $0.675^{*}$ & -0.347 \\
TMEA & $0.879^{*}$ & -0.076 & & $0.899^{*}$ & -0.102 \\
Tdry & $0.812^{*}$ & -0.102 & & $0.850^{*}$ & -0.093 \\
TMIN & $0.929^{*}$ & 0.116 & & $0.937^{*}$ & -0.114 \\
TMAX & $0.761^{*}$ & 0.092 & & 0.781 & -0.058 \\
CVT & $-0.810^{*}$ & 0.255 & & $-0.827^{*}$ & 0.226 \\
TM-m & -0.362 & -0.388 & & -0.430 & 0.341 \\
PANN & $0.877^{*}$ & 0.270 & & $0.872^{*}$ & 0.303 \\
Pdry & $0.737^{*}$ & $-0.605^{*}$ & & $0.739^{*}$ & $0.605^{*}$ \\
PMIN & $0.571^{*}$ & $-0.735^{*}$ & $0.553^{*}$ & $0.747^{*}$ \\
PMAX & $0.778^{*}$ & -0.276 & $0.777^{*}$ & -0.271 \\
CVP & -0.257 & $0.916^{*}$ & -0.259 & $0.923^{*}$ \\
PM-m & $0.508^{*}$ & $0.681^{*}$ & $0.508^{*}$ & $-0.690^{*}$ \\
\% Total variance & 53.90 & 19.50 & 55.30 & 19.60 \\
explained & & & & \\
\hline
\end{tabular}

Factors were extracted and rotated with the VARIMAX procedure with Kaiser Normalization for 15 environmental variables (see Materials and methods for nomenclature of variables). Values correspond to correlation coefficients between variables and factors. Relatively high loadings ( $|r|>0.5)$ are marked with an asterisk.

of Ctenomys although progress is being made in this sense by CJB and colleagues.

\section{Results}

The static allometric scaling of TL in relation with HBL and BM of both sexes was investigated by means of RMA regresssion. Results of the analyses are shown in Table 1 and seem to indicate an isometric scaling of tail length with body size with the exception of the relationship between female TL and HBL where $\beta_{\mathrm{RMA}}>1.0$ suggesting positive allometry. However, since ontogenetic allometry was not studied due to the lack of enough juvenile individuals (which are usually not captured) it is not possible to know if tail growth is isometric or allometric in either direction.

Raw tail length has a negative correlation with latitude ( $r=$ $-0.374, \mathrm{df}=131, \mathrm{p}<0.001$ ) as expected because of the converse Bergmann's rule followed by this rodents. We regressed the arcsin-transformed proportion of TL respect to body mass against latitude of the sampled localities. In both sexes, the proportion showed a highly significant positive correlation with latitude; that is tuco-tucos show relatively longer tails as latitude increases (Figure 2). No significant correlations were observed between TL/HBL and latitude (females, $\mathrm{p}=0.822$, $\mathrm{df}=112$; males, $\mathrm{p}=0.629$, $\mathrm{df}=110$ ). Also, no significant altitudinal clines were obtained for either of the analyzed variables.

In order to test the possible relationship of relative tail length to climatic factors we considered 14 temperature, precipitation and evapotranspiration variables as represented by the two first principal components that include almost $75 \%$ of the 
Table 3 Standardized partial regression coefficients $(b)$ and their respective $t$-values for the two principal components (PC1, PC2) derived from 13 environmental variables predicting patterns of tail length proportion distribution in males $(\mathrm{M})$ and females $(\mathrm{F})$ of Ctenomys, from a simultaneous autoregressive (SAR) model.

\begin{tabular}{llllllll}
\hline Sex & Trait & Predictor & $b$ & $t$ & $R_{\text {full }}^{2}$ & $R_{\text {pred }}^{2}$ & $\rho$ \\
\hline M & TL/HB & PC1 & -0.086 & -0.82 & 0.035 & 0.022 & 0.28 \\
& & PC2 & -0.049 & -0.46 & & & -568.1 \\
& TL/BM & PC1 & -0.311 & $-2.49 *$ & 0.182 & 0.166 & 0.47 \\
F & PC2 & -0.059 & 0.48 & & -215.3 \\
& TL/HB & PC1 & -0.212 & $-2.00^{*}$ & 0.152 & 0.133 & 0.51 \\
& & PC2 & -0.127 & -1.16 & & -626.4 \\
& TL/BM & PC1 & -0.332 & $-2.74 *$ & 0.330 & 0.293 & 0.64 \\
\hline
\end{tabular}

$A I C$, is the value of Akaike's Information Criterion; $\rho$, is the autoregressive coefficient of the SAR model; $R_{\text {full }}^{2}$, is the total coefficient of determination of the model (predictors+spatially structured error term); $R_{\text {pred }}^{2}$, refers to the effects of the predictors independently of spatial structure. *Significant at the $0.05 \%$ level.

Table 4 Standardized partial regression coefficients $(b)$ and their respective $t$-values for the best univariate models derived from 13 environmental variables predicting patterns of tail length/body mass distribution in males $(\mathrm{M})$ and females $(\mathrm{F})$ of Ctenomys, from a simultaneous autoregressive (SAR) model.

\begin{tabular}{|c|c|c|c|c|c|c|c|c|}
\hline Sex & Trait & Predictor & $b$ & $t$ & $R_{\text {full }}^{2}$ & $R_{\text {pred }}^{2}$ & $\rho$ & $A I C$ \\
\hline \multirow[t]{3}{*}{ M } & \multirow{3}{*}{ TL/BM } & PET & -0.277 & $-2.399 *$ & 0.148 & 0.134 & 0.467 & -429.216 \\
\hline & & Tdry & -0.280 & $-2.452 *$ & 0.166 & 0.144 & 0.467 & -430.116 \\
\hline & & TM-m & 0.457 & $4.019 * *$ & 0.229 & 0.216 & 0.467 & -440.137 \\
\hline \multirow[t]{3}{*}{$\mathrm{F}$} & \multirow{3}{*}{ TL/BM } & AET & -0.314 & $-2.581^{*}$ & 0.283 & 0.187 & 0.643 & -446.918 \\
\hline & & Tdry & -0.311 & $-2.799 *$ & 0.168 & 0.141 & 0.643 & -448.900 \\
\hline & & TM-m & 0.443 & $4.012 * *$ & 0.292 & 0.248 & 0.643 & -448.179 \\
\hline
\end{tabular}

$A I C$, is the value of Akaike's Information Criterion; $\rho$, is the autoregressive coefficient of the SAR model; $R_{\text {full }}^{2}$, is the total coefficient of determination of the model (predictors+spatially structured error term); $R_{\text {pred }}^{2}$, refers to the effects of the predictors independently of spatial structure. *Significant at the $0.05 \%$ level; **significant at the 0.001 level.

total variance explained in both samples as shown in Table 2 in which correlations between loadings and the variables are shown. SARs were performed separately for males and females and both tail length proportions. Except for TL/HB of males, the other proportions were significantly correlated with PC1 (Table 3). All regression slopes were negative (Table 3). However, PC1 includes most of the climatic variables considered (Table 2) many of which are colinear and significantly correlated (Appendices 1 and 2) thus, the analyses have not great explanatory power. To explore more thoroughly the relationship between tail proportions and environmental factors, we performed SARs between tail proportions and different combinations climatic variables having the highest and lowest Eigenvector loadings in random combinations of 1, 2, 3 and 4 variables using the Akaike Information Criterion to select the best models that predict variation in tail proportion with respect to body mass in both sexes. The best models are shown in Table 4 . In the case of males, PET, Tdry and TM-m were the best univariate models with coefficients for the latter two being the most statistically significant (Table 4). No multivariate model showed higher AIC values. Similarly in females, TL/BM was best explained by three univariate models (Table 4) also including Tdry and TM-m, although AET and not PET was significantly correlated with tail proportion.
The four climatic variables are highly significantly correlated with latitude (see Appendices 1 and 2).

\section{Discussion}

Variation in body size and other morphological traits of animals along geographical gradients is one of the most interesting and least understood patterns in nature (Lomolino et al. 2006a). A number of these trends have been identified and are usually referred to as "ecogeographical rules" (Ashton 2001, Lomolino et al. 2006b, Millien et al. 2006, Gaston et al. 2008). Of these, Bergmann's and Allen's rules refer specifically to body size and body proportions of protruding appendages, respectively (Bergmann 1847, Allen 1877, 1905). We chose to analyze variation in relative tail length for reasons discussed below.

Although Bergmann's rule has received much attention from researchers during more than 160 years and a wealth of information on Bergmannian patterns in endotherms and ectotherms is available (Blackburn et al. 1999, Ashton et al. 2000, Freckleton et al. 2003, Meiri and Dayan 2003, Medina et al. 2007), Allen's rule has been rather neglected despite the fact that the proposed mechanism for explaining the trend to 
shorter appendages toward higher latitudes is essentially the same for Bergmann's rule, i.e., conservation or dissipation of heat (Allen 1877, Lomolino et al. 2006a).

Another problem regarding Allen's rule as well as Bergmann's and other ecogeographical rules is whether they apply to inter- or intraspecific variation (Blackburn et al. 1999) and if this is the case, whether mechanisms responsible for the trends are similar or different. In this sense, Watt et al. (2010) have discussed that Bergmann's rule is probably a "concept cluster" (Peet 1974, see also Lawton 1999) since it has been applied at different taxonomic levels and many underlying mechanisms have been proposed. This may well be applied to Allen's rule too. Most of the published accounts of Allen trends have been intraspecific, tracing relative proportions of protruding body parts across the latitudinal or altitudinal distribution of a species, with few exceptions (e.g., Cartar and Morrison 2005). By far, the most thorough interspecific study of Allen's rule is that of Nudds and Oswald (2007) in gulls and terns. The authors conclude that the mechanism explaining Allen's rule, is the reduction of thermoregulatory cost during the coldest part of the breeding season of these species. It is interesting to note that variation occurred in the exposed leg bone elements and not in the feathered elements, reinforcing the thermoregulatory interpretation (Nudds and Oswald 2007).

In rodents, the more important structure involved in thermoregulatory function is the tail, which serves as a heatloss organ (Thorington 1966, Hickman 1979, Young and Dawson 1981, Dawson and Keber 2007). For example, the Sciurognath Geomys pocket gophers facilitate heat loss during heat stress by increasing blood circulation in their naked tails through which they can lose up to $30 \%$ of their heat production (McNab 1966). Geographic variation in heat loading has produced reduction of body size or increase in tail length in these subterranean rodents (McNab 1966). Tuco-tucos (Hystricognathi) share with pocket gophers many adaptations to the subterranean lifestyle (Nevo 1999) although less is known about thermoregulatory mechanisms in this genus. Tuco-tucos tail which has sensory functions, is almost hairless and, if it is used in thermoregulation, is a good candidate to show variation in length according to Allen's rule.

The case of tuco-tucos reported here is significant in more than one aspect. First, the observed trend for relative tail length is inverted with respect to Allen's rule expectations. Our first hypothesis was that, being fully subterranean thus being much less affected by surface climatic conditions than cursorial species, Allen's rule should not operate in this genus, and that was the case. However, instead of lacking a geographical trend, tuco-tucos tend to have relatively longer tails at higher latitudes. Tuco-tucos as other subterranean mammals, maintain fairly constant microclimatic conditions of their burrows, within which they spent $>95 \%$ of the time (Reig et al. 1990) through specialized behaviors (Nevo 1999, Burda 2007). The degree of exposure to external environmental conditions is minimal.

Although only three species have been adequately studied in this respect their comparison is revealing. Ctenomys torquatus and C. talarum were distributed between $25^{\circ}-35^{\circ}$ and $35^{\circ}-40^{\circ}$, respectively $(0-200 \mathrm{~m})$, and inhabited widely different environments. They maintain constant burrow temperatures of $20^{\circ}-22^{\circ} \mathrm{C}$ throughout the year (Medina et al. 2007). More notorious is the case of C. fulvus, which inhabits the Chilean Puna $\left(20^{\circ}-26^{\circ} \mathrm{S}\right)$ in isolated oases up to 4000 m elevation; this species maintains burrow temperatures between $19^{\circ} \mathrm{C}$ and $25^{\circ} \mathrm{C}$, when the above-ground temperature varies from less than $4^{\circ} \mathrm{C}$ to more than $45^{\circ} \mathrm{C}$ with a mean thermal amplitude of ca. $38^{\circ} \mathrm{C}$ during the day and independently of season (Cortés et al. 2000). Tuco-tuco burrows maintain more constant temperatures than those of other studied subterranean species, such as African bathyergids (Reichman and Smith 1990, Roper et al. 2001, Sumbera et al. 2004, Burda 2007). It is thus possible that all species maintain similar temperature conditions within their burrows independently of latitude and altitude (Reig et al. 1990). It has also been reported for Ctenomys talarum that seasonal changes in fur length may help thermal stability (Cutrera and Antinuchi 2004).

This almost independence of external conditions suggests that classical ecogeographic rules based on thermoregulatory mechanisms, such as Allen's, do not need to operate in tucotucos but in fact do occur. Furthermore, body size of Ctenomys species decreases significantly toward higher latitudes and lower temperatures, opposing Bergmann's rule (Medina et al. 2007). Medina et al. (2007) explained this inverse pattern by temperature-independent mechanisms, such as geographic variation in resources, seasonality and intensity of predation.

Because the relative tail length trend observed in tuco-tucos also inverts Allen's rule, it is tempting to attribute the pattern as a consequence of the converse Bergmannian pattern. As shown in results, predictors of relative tail length were Tdry, AET, PET (negative) and TM-m (positive). Tail is relatively longer at lower temperatures, lower primary productivity and less ambient energy (two correlates of AET and PET), and high thermal amplitude. This combination of factors indicates progressively higher seasonality, one of the factors suggested to produce the inverse Bergmann's cline (Medina et al. 2007). It is thus proposed that the inversion of Allen's rule in Ctenomys is a consequence of negative allometric growth of the tail, and is probably independent of external ambient conditions. As shown in the results, raw tail length is not correlated with latitude while body length and body mass are strongly negatively correlated with latitude thus, while body size decreases progressively towards south, tail length does not, indirectly suggesting that negative ontogenetic allometry (species attaining larger sizes having a slower tail growth) could be the subjacent cause of the converse Allenian pattern which in turn, would result from the inversion of Bergmann's rule.

\section{Acknowledgements}

We are grateful to all students and colleagues that helped during field work. Financial support from CNPq, FAPERJ, FIOCRUZ and FONCyT through grants to CJB is especially acknowledged. Rocio Hassan read a previous draft of this manuscript and her important contributions were incorporated to the final version. The comments of the Associate Editor and two anonymous reviewers improved the manuscript substantially. 


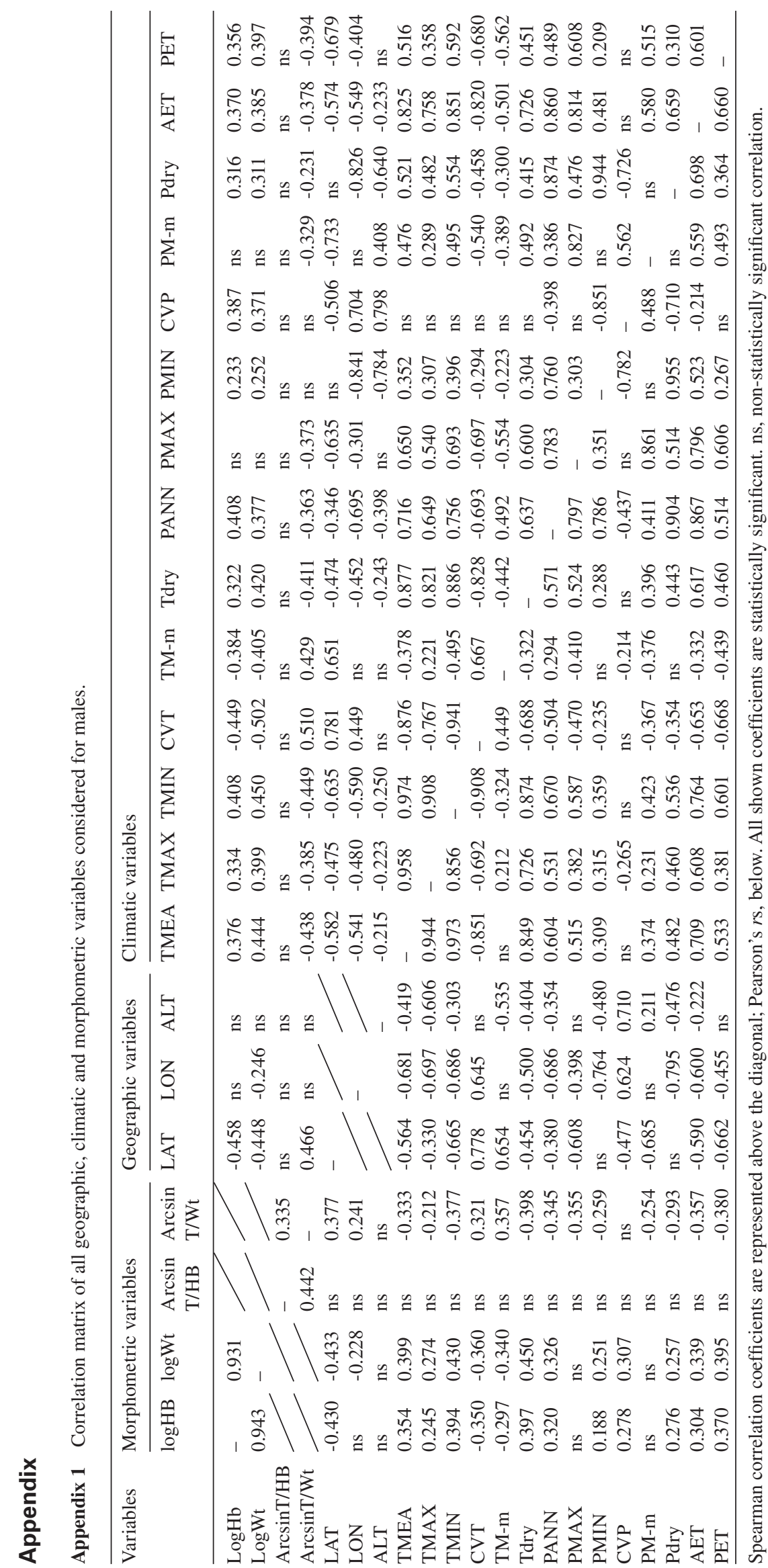




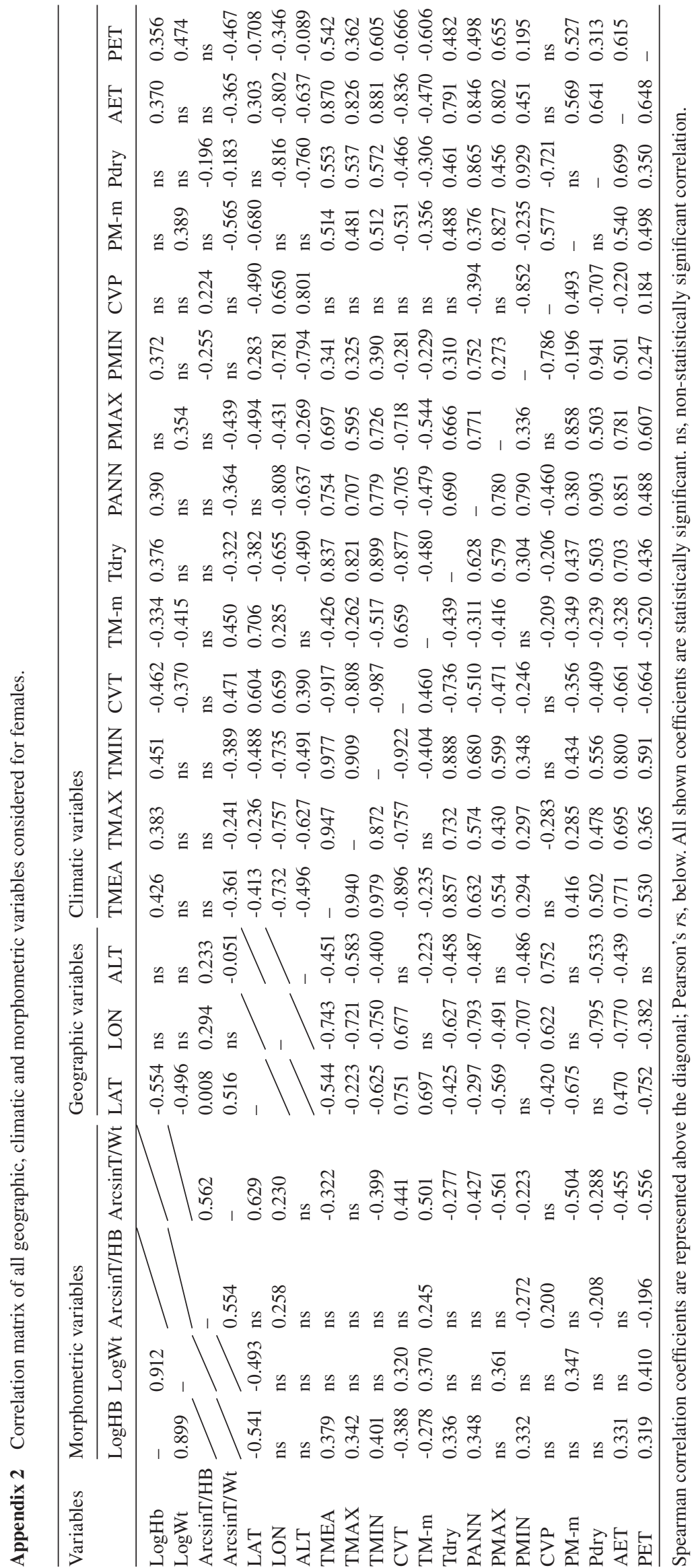




\section{References}

Ahn, C.H. and R. Tateishi. 1994a. Development of a global 30-minute grid Potential Evapotranspiration data set. J. Jpn. Soc. Photogramm. Remote Sens. 33: 12-21.

Ahn, C.H. and R. Tateishi. 1994b. Estimation of potential evapotranspiration for global data sets. Proc. ISPRS Commun. IV Symp. Mapp. Geogr. Inf. Syst., May 31-June 3, Athens, Georgia, USA 30/4. pp. 586-593.

Allen, J.A. 1877. The influence of physical conditions in the genesis of species. Radical Rev. 1: 108-140.

Allen, J.A. 1905. The evolution of species through climatic conditions. Science 22: 661-668.

Ashton, K.G. 2001. Are ecological and evolutionary rules being dismissed prematurely? Divers. Distrib. 7: 289-295.

Ashton, K.G., M.C. Tracy and A. de Queiroz. 2000. Is Bergmann's rule valid for mammals? Am. Nat. 156: 390-415.

Bergmann, C. 1847. Über die Verhältnisse der Warmoekonomie der Thiere zu ihrer Grösse. Götinger Studien 3 Pt.1: 595-708.

Bidau, C.J. 2006. Family Ctenomyidae. In: (R.J. Bárquez, M.M. Díaz and R.A. Ojeda, eds.) Mamíferos de Argentina. Sistemática y Distribución. Sociedad Argentina para el Estudio de los Mamíferos. Tucumán, Argentina. pp. 212-231.

Bidau, C.J. 2011. Genus Ctenomys. In: (J.L. Patton, ed.). The mammals of South America. Vol 3. University of Chicago Press, Chicago, IL. In press.

Blackburn, T.M., K.J. Gaston and N. Loder. 1999. Geographic gradients in body size: a clarification of Bergmann's rule. Divers. Distrib. 5: 165-174.

Bohonak, A.J. and K. van der Linde. 2004. RMA: software for Reduced Major Axis regression. Java version. http://www. kimvdlinde.com/professional/rma.html.

Bried, J. and P. Jouventin. 1997. Morphological and vocal variation among subspecies of the black-faced sheathbill. Condor 99: $818-825$.

Burda, H. 2007. Microclimate in burrows of subterranean rodents revisited. In: (S. Begall, H. Burda and C.E. Sleich, eds.) Subterranean rodents. News from underground. Springer, BerlinHeidelberg. pp. 21-33.

Burnham, K.P. and D.R. Anderson. 2002. Model selection and multimodel inference: a practical-theoretic approach. 2nd ed. Springer-Verlag, New York.

Busch, C., C. Antinuchi, J.C. del Valle, M.J. Kittlein, A.I. Malizia, A.I. Vassallo and R.R. Zenuto. 2000. Population ecology of subterranean rodents. In: (E.A. Lacey, J.L. Patton and G.N. Cameron, eds.) Life underground. The biology of subterranean rodents. The University of Chicago Press, Chicago, IL. pp. 183-226.

Cartar, R.V. and R.I.G. Morrison. 2005. Metabolic correlates of leg length in breeding arctic shorebirds: the cost of getting high. J. Biogeogr. 32: 377-382.

Clarke, M.R.B. 1980. The reduced major axis of a bivariate sample. Biometrika 67: 441-446.

Contreras, J.R. and C.J. Bidau. 1999. Líneas generales del panorama evolutivo de los roedores excavadores sudamericanos del género Ctenomys (Mammalia, Rodentia, Caviomorpha, Ctenomyidae). Ciencia Siglo XXI 1: 1-22.

Cortés, A., E. Miranda, M. Rosenmann and J.R. Rau. 2000. Thermal biology of the fossorial rodent Ctenomys fulvus from the Atacama desert, northern Chile. J. Therm. Biol. 25: 425-430.

Cramer, W.P. and R. Leemans. 2001. Global 30-year mean monthly climatology, 1930-1960, Version 2.1 (Cramer and Leemans). Data set. http://www.daac.ornl.gov. Oak Ridge National Laboratory Distributed Active Archive Center, Oak Ridge, Tennessee, USA).
Cutrera, A.P. and C.D. Antinuchi. 2004. Cambios en el pelaje del roedor subterráneo Ctenomys talarum: posible mecanismo térmico compensatorio. Rev. Chil. Hist. Nat. 77: 235-242.

Dawson, N.J. and A.K. Keber. 2007. Physiology of heat loss from an extremity: the tail of the rat. Clin. Exp. Pharmacol. 6: 69-80.

Diniz-Filho, J.A.F., L.M. Bini and B.A. Hawkins. 2003. Spatial autocorrelation and red herrings in geographical ecology. Global Ecol. Biogeogr. 12: 53-64.

Ellison, G.T.H., P.J. Taylor, H.A. Nix, G.N. Bronner and J.P. McMahon. 1993. Climatic adaptation of body size among pouched mice (Saccostomus campestris: Cricetidae) in the southern African subregion. Global Ecol. Biogeogr. 3: 41-47.

Freckleton, R.P., P.H. Harvey and M. Pagel. 2003. Bergmann's rule and body size in mammals. Am. Nat. 161: 821-825.

Gaston, K.J., S.C. Chown and K.L. Evans. 2008. Ecogeographical rules: elements of a synthesis. J. Biogeogr. 35: 483-500.

Griffing, J.P. 1974. Body measurements of black-tailed jackrabbits of Southeastern New Mexico with implications of Allen's rule. J. Mammal. 55: 674-678.

Hawkins, B.A. and J.A.F. Diniz-Filho. 2004. 'Latitude' and geographic patterns in species richness. Ecography 27: 268-272.

Hickman, G.C. 1979. The mammalian tail: a review of functions. Mammal Rev. 9: 143-157.

Jones, J., C.E. Gibb, S.C. Millard, J.J. Barg, M.K. Girvan, M.L. Veit, V.L. Friesen and R.J. Robertson. 2005. Multiple selection pressures generate adherence to Bergmann's rule in a Neotropical migratory songbird. J. Biogeogr. 32: 1827-1833.

Kline, P. 1994. An easy guide to factor analysis. Routledge, London.

Laiolo, P. and A. Rolando. 2001. Ecogeographic correlates of morphometric variation in the red-billed chough Pyrrhocorax pyrrhocorax and the alpine chough Pyrrhocorax graculus. Ibis 143: 602-616.

Lawton, J.H. 1999. Are there general laws in ecology? Oikos 84: 177-192.

Legendre, P. 1993. Spatial autocorrelation: trouble or new paradigm? Ecology 74: 1659-1673.

Legendre, P. and L. Legendre. 1998. Numerical ecology. 2nd ed. Elsevier, Amsterdam. pp. 870.

Lindsay, S.L. 1987. Geographic size and non-size variation in Rocky Mountain Tamiasciurus hudsonicus: significance in relation to Allen's rule and vicariant biogeography. J. Mammal. 68: 39-48.

Lomolino, M.V., B.R. Riddle and J.H. Brown. 2006a. Biogeography. 3rd ed. Sinauer Associates, Sunderland, MA.

Lomolino, M.V., D.F. Sax, B.R. Riddle and J.H. Brown. 2006b. The island rule and a research agenda for studying ecogeographical patterns. J. Biogeogr. 33: 1503-1510.

Mayr, E. 1999. Systematics and the origin of species from the viewpoint of a zoologist. Harvard University Press, Cambridge, MA, London.

McGillivray, W.B. 1989. Geographic variation in size and reverse size dimorphism of the great horned owl in North America. Condor 91: 777-786.

McNab, B.K. 1966. The metabolism of fossorial rodents: a study of convergence. Ecology 47: 712-733.

Medina, A.I., D.A. Martí and C.J. Bidau. 2007. Subterranean rodents of the genus Ctenomys (Caviomorpha, Ctenomyidae) follow the converse to Bergmann's rule. J. Biogeogr. 34: 1439-1454.

Meiri, S. and Y. Dayan. 2003. On the validity of Bergmann's rule. J. Biogeogr. 30: 331-351.

Merilä, J. 1997. Quantitative trait and allozyme divergence in the Greenfinch (Carduelis chloris, Aves: Fringillidae). Biol. J. Linn. Soc. 61: 243-266. 
Millien, V., S.K. Lyons, L. Olson, F.A. Smith, A.W. Wilson and Y. Yom-Tov. 2006. Ecotypic variation in the context of global climate change: revisiting the rules. Ecol. Lett. 9: 853-869.

Mirol, P.M., M.D. Giménez, J.B. Searle, C.J. Bidau and C.G. Faulkes. 2010. Population and species boundaries in the South American subterranean rodent Ctenomys in a dynamic environment. Biol. J. Linn. Soc. 100: 368-393.

Mitchell, G.J. 1971. Measurements, weights, and carcass yields of pronghorns in Alberta. J. Wildl. Manage. 35: 76-85.

Nevo, E. 1999. Mosaic evolution of subterranean mammals. Regression, progression and global convergence. Oxford University Press, Oxford.

Nudds, R.L. and S.A. Oswald. 2007. An interspecific test of Allen's rule: evolutionary implications for endothermic species. Evolution 61: 2839-2848.

Olalla-Tárraga, M.A., M.A. Rodríguez and B.A. Hawkins. 2006. Broad-scale patterns of body size in squamate reptiles of Europe and North-America. J. Biogeogr. 33: 781-793.

Peet, R. 1974. The measurement of species diversity. Annu. Rev. Ecol. Syst. 5: 285-302.

Ramey, C.A. and D.J. Nash. 1976. Geographic variation in alberti squirrel (Sciurus alberti). Southwest. Nat. 21: 135-139.

Rangel, T.F.L.V.B., J.A.F. Dinz-Filho and L.M. Bini. 2006. Towards an integrated computational tool for spatial analysis in macroecology and biogeography. Global Ecol. Biogeogr. 15: 321-327.

Raveling, D.G. and D.W. Warner. 1978. Geographic variation of yellow warblers killed at a TV tower. Auk 95: 73-79.

Ray, C. 1960. The application of Bergmann's and Allen's rules to the poikilotherms. J. Morphol. 106: 85-108.

Reichman, O.J. and S.C. Smith. 1990. Burrows and burrowing behavior in mammals. In: (H.H. Genoways, ed.) Current mammalogy. Plenum Press, New York and London. pp. 197-244.

Reig, O.A., C. Busch, M.O. Ortells and J.R. Contreras. 1990. An overview of evolution, systematics, population biology, cytogenetics, molecular biology and speciation in Ctenomys. In: (E. Nevo and O.A. Reig, eds.) Evolution of subterranean mammals at the organismal and molecular levels. Alan R. Liss, New York. pp. 71-96.

Rodríguez, M.A., L.L. López-Sañudo and B.A. Hawkins. 2006. The geographic distribution of mammal body size in Europe. Global Ecol. Biogeogr. 15: 173-181.

Roper, T.J., N.C. Bennett, L. Conradt and A.J. Molteno. 2001. Environmental conditions in burrows of two species of African mole-rat, Georhychus capensis and Cryptomys damarensis. J. Zool. 254: 101-107.
Rosenzweig, M.L. 1968. The strategy of body size in mammalian carnivores. Am. Midl. Nat. 80: 299-315.

Salthe, S.N. and M.L. Crump. 1977. A Darwinian interpretation of hindlimb variability in frog populations. Evolution 31: 737-749.

Sedlácek, F. 2007a. Adaptive physiological mechanisms in the underground dwellers. In: (S. Begall, H. Burda and C.E. Sleich, eds.) Subterranean rodents. News from undergound. Springer Verlag, Berlin-Heidelberg. pp. 13-19.

Sedlácek F. 2007b. New data on metabolic parameters in subterranean rodents. In: (S. Begall, H. Burda and C.E. Sleich, eds.) Subterranean rodents. News from undergound. Springer Verlag, Berlin-Heidelberg. pp. 35-47.

Serrat, M.A., D. King and C.O. Lovejoy. 2008. Temperature regulates limb length in homeotherms by directly modulating cartilage growth. Proc. Natl. Acad. Sci. USA 105: 19348-19353.

Snow, D.W. 1954. Trends in geographical variation in Palaearctic members of the genus Parus. Evolution 8: 19-28.

Stevenson, R.D. 1986. Allen's rule in North American rabbits (Sylvilagus) and hares (Lepus) is an exception, not a rule. J. Mammal. 67: 312-316.

Sumbera, R., W.N. Chitaukali, M. Elichová, J. Kubová and H. Burda. 2004. Microclimatic stability in burrows of an Afrotropical solitary bathyergid rodent, the silvery mole-rat (Heliophobius argenteocinereus). J. Zool. 263: 409-416.

Thorington, R.W. Jr. 1966. The biology of rodent tails: a study of form and function. Technical Report (Arctic Aeromedical Laboratory (U.S.) AAL-TR - 65-8, Fort Wainwright, Alaska.

Tilkens, M.J., C. Wall-Scheffler, T.D. Weaver and K. SteudelNumber. 2007. The effects of body proportions on thermoregulation: an experimental assessment of Allen's rule. J. Hum. Evol. 53: 286-291.

Vrba, E.S. 1996. Climate, heterochrony, and human evolution. J. Anthropol. Res. 52: 1-28.

Watt, C., S. Mitchell and V. Salewski. 2010. Bergmann's rule; a concept cluster? Oikos 119: 89-100.

Wiggington, J.D. and F.S. Dobson. 1999. Environmental influences on geographic variation in body size of western bobcats. Can. J. Zool. 77: 802-813.

Yom-Tov, Y., S. Yom-Tov, J. Wright, C.J.R. Thorne and R. Du Feu. 2006. Recent changes in body weight and wing length among some British passerine birds. Oikos 112: 91-101.

Young, A.A. and N.J. Dawson. 1981. Evidence for on-off control of heat dissipation from the tail of the rat. Can. J. Physiol. Pharmacol. 60: 392-398. 